\title{
Alpha and beta-Thalassemia mutations in Hubei area of China
}

\author{
Yaowu Zhu', Na Shen ${ }^{1}$, Xiong Wang ${ }^{1}$, Juan Xiao ${ }^{2^{*}}$ and Yanjun Lu ${ }^{1 *}$ (ID
}

\begin{abstract}
Background: Thalassemia is a group of inherited hemoglobic disorders resulting from defects in the synthesis of one or more of the hemoglobin chains, which is one of the most prevalent inherited disorders in southern China. Only few studies reported the molecular characterization of $a-$ and $\beta$-Thalassemia in Hubei Province in the central of China.

Methods: A total of 4889 clinically suspected cases of thalassemia were analyzed by Gap-PCR, PCR-based reverse dot blot (RDB).

Results: 1706 (33.8\%) subjects harbored thalassemia mutations, including 539 (11.0\%) subjects with a-thalassemia, $1140(23.3 \%)$ subjects with $\beta$-thalassemia mutations, and $25(0.51 \%)$ subjects with both $a$ - and $\beta$-thalassemia mutations. Seven genotypes of a-thalassemia mutations and 29 genotypes of $\beta$-thalassemia mutations were characterized. - SEA $/$ aa (66.05\%), $-a^{3.7} / \mathrm{aa}(24.12 \%)$, and $-a^{4.2} / \mathrm{aa}(3.71 \%)$ accounted for $93.88 \%$ of the $a$-thalassemia mutations. $\beta I V S-I I-654 / \beta N$, $\beta C D 41-42 / \beta N, \beta C D 17 / \beta N, \beta C D 27-28 / \beta N, \beta C D 71-72 / \beta N, \beta-28 / \beta N, \beta-29 / \beta N, \beta C D 43 /$ $\beta N, \beta E / \beta N$, accounting for $96.40 \%$ of all $\beta$-thalassemia genotypes. Furthermore, mean corpuscular volume (MCV) and mean corpuscular $\mathrm{Hb}(\mathrm{MCH})$ were sensitive markers for both $\beta$-thalassemia and a-thalassemia with -- SEA /aa, but not $-a^{3.7} / a a$ and $-a^{4.2} / a a$. Conclusions: Our data indicated great heterogeneity and extensive spectrum of thalassemias in Hubei province of China.
\end{abstract}

Keywords: Thalassemia, Globin mutation, Prevalence Spectrum, Hubei region

\section{Background}

Thalassemia is a group of autosomal recessive disorders with varied phenotype, which are caused by human globin gene synthesis disorders [1], including $\alpha$-thalassemia and $\beta$-thalassemia [2]. No effective treatment for patients with severe thalassemia has been reported, except bone marrow transplantation, which creates an enormous burden on the family and the society. Application of thalassemia carrier screening and prenatal diagnosis to prevent the delivery of newborn with severe thalassemia is important.

In China, thalassemia is most frequent in Guangdong, Guangxi, Hainan provinces [3, 4]. The prevalence of $\alpha-$ thalassemia, $\beta$-thalassemia, and both $\alpha$ - and $\beta$-thalassemia was $8.53,2.54$, and $0.26 \%$ respectively in a cohort of 13,397

\footnotetext{
* Correspondence: 552145919@qq.com; 2000@163.com

${ }^{2}$ Department of Obstetrics and Gynecology, Tongji Hospital, Tongji Medical College, Huazhong University of Science and Technology, Wuhan 430030 China

'Department of Laboratory Medicine, Tongji Hospital, Tongji Medical College, Huazhong University of Science and Technology, Wuhan 430030, China
}

consecutive samples from Guangdong province [5]. In Guangxi province, the prevalence varied to be $24.07,15.35$, and $6.64 \%$ in 47,500 screened individuals from Baise region [6]. In Hainan province, prevalence of $\alpha$-thalassemia increased to $53.45 \%$ in 8600 subjects of the Li people, however, it was only $12.16 \%$ in 9800 Han people [7]. These studies reported diverse spectrums of globin mutations in different geographical distribution regions with different ethnic populations [8]. Ethnic background and screening strategy may partially explain these differences.

Hubei province is located in central of China and the Han people accounts for the majority. Hubei is about $1000 \mathrm{~km}$ away from Guangxi and Guangdong provinces (Fig. 1). The prevalence of $\alpha$-thalassemia and $\beta$ thalassemia in neonates has been investigated by $\mathrm{Cai}$ WQ et al., [9] and Xiong Q et al., [10] respectively in Wuhan area of Hubei province. Herein, we performed a largescale survey to reveal the $\alpha$ - and $\beta$-thalassemia mutations in 4889 suspected cases of thalassemia in Hubei province including both Wuhan area and around cities. 


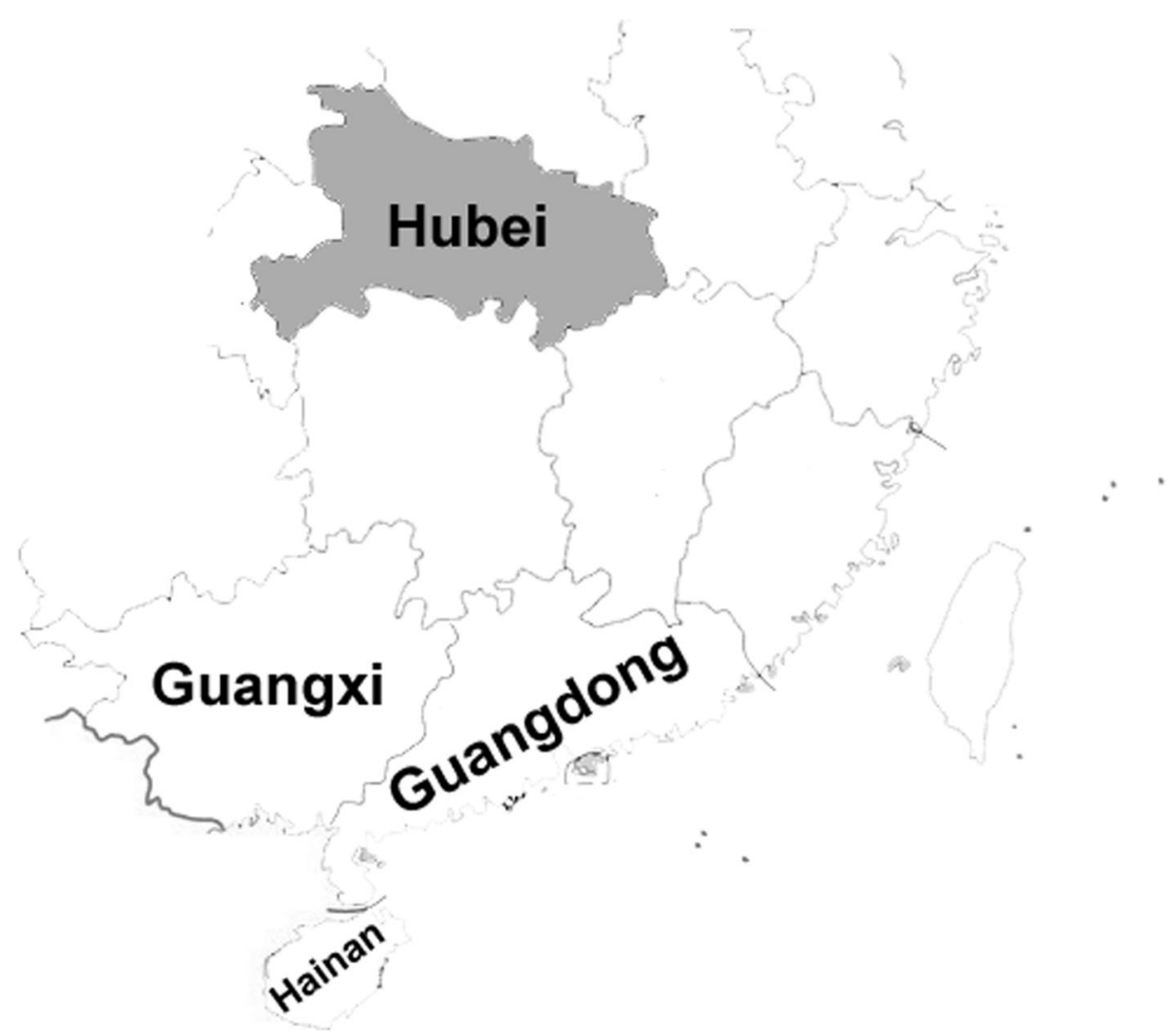

Fig. 1 The part of map of southeastern China, which was drawn by Photoshop 6.0 software

\section{Methods}

\section{Human subjects}

From January 2013 to October 2018, 4889 suspected cases of thalassemia (1884 males and 3005 females) had molecular testing for thalassemia from departments of Paediatrics, Hematology, and Obstetrics \& Gynecolog in our hospital. The relatives of patients of thalassemia were excluded. The inclusion criteria include: (1) microcytosis and hypochromia blood routine test, or (2) positive family history. The age of the patients ranged from 1 to 88 years old. Information records of sex, age and related medical examination were available in our Electronic Medical Record Information System. This study was approved by the Medical Ethics Committee of Tongji Hospital, Tongji Medical College, Huazhong University of Science and Technology. All procedures were carried out in accordance with ethical guidelines for human subject's research.

\section{Hematological analysis}

Two $\mathrm{ml}$ peripheral venous blood samples were collected with EDTA anticoagulants, and determined with SYSMEX XS800i automatic blood cell analyzer (Kobe, Japan).

\section{Genetic analysis}

The DNA was extracted using the DNA blood extraction kit (Tiangen Bio-Tech Co. Ltd., Beijing, China) according to the manufacturer's instructions. Gap-polymerase chain reaction (gap-PCR) and PCR-reverse dot-blot assays were used to analyze $\alpha$-thalassemia and $\beta$-thalassemia mutations with commercial kits from Yaneng Biosciences (Shenzhen, Guangdong, China) as previously described [11].

\section{Results}

One thousand seven hundred six subjects were detected with thalassemia mutations, including 539 (11.0\%) subjects of $\alpha$-thalassemia mutation alone, 1140 (23.3\%) subjects of $\beta$-thalassemia mutation alone and $25(0.51 \%)$ subjects of both $\alpha$ - and $\beta$-thalassemia mutations.

Among the 539 cases with $\alpha$-thalassemia mutations, seven types of $\alpha$ globin gene deletion were detected (Table 1 ). ${ }_{-}-\mathrm{SEA} / \alpha \alpha$ was the most frequent genotype, accounting for more than half of all $\alpha$-thalassemia genotypes (66.05\%). $-\alpha^{3.7} / \alpha \alpha$ was the second highest genotype and accounted for $24.12 \%$. In addition, the proportion of $-\alpha^{4.2} / \alpha \alpha$ was $3.71 \%$, and the proportions of compound heterozygous $-\alpha .7 /-{ }^{3 .}$ SEA, $-\alpha^{4.2} /-{ }^{S E A}$ genotype were $3.53,1.67 \%$ respectively. Also a small proportion of the homozygous $-\alpha^{3.7} /-\alpha^{3.7}(0.74 \%)$ and $-\alpha^{4.2} /-\alpha^{4.2}(0.19 \%)$ were found in our study. 
Table 1 Genotype, number of subjects and frequency of thalassemia deletions

\begin{tabular}{|c|c|c|}
\hline Genotype & $n$ & Frequency (\%) \\
\hline \multicolumn{3}{|l|}{ a-thalassemia } \\
\hline$-{ }_{--} \mathrm{SEA} / \mathrm{aa}$ & 356 & 66.05 \\
\hline$-a^{3.7} / a a$ & 130 & 24.12 \\
\hline$-a^{4.2} / a a$ & 20 & 3.71 \\
\hline$-a^{3.7} /-a^{3.7}$ & 4 & 0.74 \\
\hline$-a^{4.2} /-a^{4.2}$ & 1 & 0.19 \\
\hline$-a^{3.7} /-_{-}$SEA & 19 & 3.53 \\
\hline$-a^{4.2} /-{ }_{-}$SEA & 9 & 1.67 \\
\hline Total a-thalassemia & 539 & 100 \\
\hline \multicolumn{3}{|l|}{$\beta$-thalassemia } \\
\hline \multicolumn{3}{|l|}{ Heterozygote } \\
\hline$\beta I V S-1 I-654 / \beta N$ & 546 & 47.89 \\
\hline$\beta C D 41-42 / \beta N$ & 284 & 24.91 \\
\hline$\beta C D 17 / \beta N$ & 158 & 13.86 \\
\hline$\beta C D 27-28 / \beta N$ & 32 & 2.81 \\
\hline$\beta C D 71-72 / \beta N$ & 28 & 2.46 \\
\hline$\beta-28 / \beta N$ & 20 & 1.75 \\
\hline$\beta C D 43 / \beta N$ & 13 & 1.14 \\
\hline$\beta-29 / \beta N$ & 10 & 0.88 \\
\hline$\beta E / \beta N$ & 8 & 0.7 \\
\hline$\beta C D 14-15 / \beta N$ & 3 & 0.26 \\
\hline$\beta I V S-I-1 / \beta N$ & 3 & 0.26 \\
\hline$\beta I V S-1-5 / \beta N$ & 2 & 0.18 \\
\hline ßcap & 2 & 0.18 \\
\hline Total $\beta$-thalassemia & 1109 & 97.28 \\
\hline \multicolumn{3}{|l|}{ Compound heterozygote } \\
\hline$\beta C D 41-42 / \beta I V S-I I-654$ & 5 & 0.44 \\
\hline$\beta-28 / \beta I V S-1 \mid-654$ & 4 & 0.35 \\
\hline$\beta C D 17 / \beta I V S-I I-654$ & 3 & 0.26 \\
\hline$\beta C D 41-42 / \beta C D 17$ & 1 & 0.08 \\
\hline$\beta C D 71-72 / \beta C D 14-15$ & 1 & 0.08 \\
\hline$\beta-29 / \beta I V S-1 I-654$ & 1 & 0.08 \\
\hline$\beta E$ / $\beta I V S-I I-654$ & 1 & 0.08 \\
\hline$\beta C D 27-28 / \beta I V S-I I-654$ & 1 & 0.08 \\
\hline$\beta E / \beta C D 27-28$ & 1 & 0.08 \\
\hline$\beta-28 / \beta C D 17$ & 1 & 0.08 \\
\hline$\beta C D 71-72 / \beta C D 17$ & 1 & 0.08 \\
\hline Total Compound heterozygote & 20 & 1.75 \\
\hline \multicolumn{3}{|l|}{ Homozygote } \\
\hline BIVS-II-654/ßIVS-II-654 & 6 & 0.53 \\
\hline$\beta C D 41-42 / \beta C D 41-42$ & 2 & 0.18 \\
\hline$\beta C D 17 / \beta C D 17$ & 1 & 0.08 \\
\hline$\beta-29 / \beta-29$ & 1 & 0.08 \\
\hline
\end{tabular}

Table 1 Genotype, number of subjects and frequency of thalassemia deletions (Continued)

\begin{tabular}{|c|c|c|}
\hline Genotype & $n$ & Frequency (\%) \\
\hline$\beta C D 27-28 / \beta C D 27-28$ & 1 & 0.08 \\
\hline Total Homozygote & 11 & 0.96 \\
\hline \multicolumn{3}{|l|}{$a$ - and $\beta$-thalassemia } \\
\hline$-a^{3.7} / a a$ and $\beta I V S-11-654 / \beta N$ & 7 & 28 \\
\hline$-a^{3.7} / a a$ and $\beta C D 41-42 / \beta N$ & 4 & 16 \\
\hline _-SEA $/$ aa and IVS-II-654/BN & 4 & 16 \\
\hline${ }_{--} \mathrm{SEA} / \mathrm{aa}$ and $\beta C D 41-42 / \beta N$ & 3 & 12 \\
\hline$-a^{4.2} / a a$ and IVS-II-654/ßN & 2 & 8 \\
\hline$-a^{3.7} / a a$ and $\beta C D 17 / \beta N$ & 1 & 4 \\
\hline$-a^{3.7} / a a$ and $\beta E / \beta N$ & 1 & 4 \\
\hline${ }_{-} \mathrm{SEA} / \mathrm{aa}$ and $\beta C D 17 / \beta N$ & 1 & 4 \\
\hline${ }_{--} \mathrm{SEA} / \mathrm{aa}$ and $\beta I V S-1-5 / \beta N$ & 1 & 4 \\
\hline$-a^{3.7} /--^{\text {SEA }}$ and $\beta C D 41-42 / \beta N$ & 1 & 4 \\
\hline Total $a-$ and $\beta$-thalassemia & 25 & 100 \\
\hline
\end{tabular}

Of the 1140 cases who were with $\beta$-thalassemia mutations, twenty-nine different genotypes were found, including 1109 heterozygotes, 20 compound heterozygotes and 11 homozygotes, accounting for $97.28,1.75$ and $0.96 \%$, respectively (Table 1 ). $\beta I V S-I I-654 / \beta N$ was the most common genotype, accounting for $47.89 \%$ of all $\beta$-thalassemia genotypes. Most of the remaining genotypes were $\beta C D 41-42 / \beta N, \beta C D 17 / \beta N, \beta C D 27-28 / \beta N, \beta C D 71-$ $72 / \beta \mathrm{N}, \quad \beta-28 / \beta \mathrm{N}, \quad \beta-29 / \beta \mathrm{N}, \quad \beta C D 43 / \beta \mathrm{N}, \quad \beta E / \beta \mathrm{N}$. Overall, these nine genotypes accounted for $96.40 \%$ of all $\beta$-thalassemia genotypes. The most common compound heterozygous genotype was $\beta C D 41-42 / \beta I V S-I I-654$ $(0.44 \%)$, and the most common homozygous mutation was $\beta I V S-I I-654 / \beta I V S-I I-654$ (0.53\%) in Hubei region.

In the 25 cases that had been found to carry compound $\alpha / \beta$-thalassemia mutations, 10 types of gene mutation combinations were revealed, the specific phenotype, frequency was shown in Table 1. Among them, the three most common compound genotypes were $-\alpha^{3.7} / \alpha \alpha$ and $\beta$ IVS-II-654/ $\beta \mathrm{N},-\alpha^{3.7} / \alpha \alpha$ and $\beta C D 41-42 / \beta \mathrm{N}$, -_SEA $/ \alpha \alpha$ and IVS-II-654/ $\beta \mathrm{N}$ and accounted for $60 \%$. In addition, one case with the compound $\alpha$-thalassemia mutation $-\alpha^{3.7} /{ }_{-}$SEA and the $\beta$ thalassemia heterozygote $\beta C D 41-42 / \beta \mathrm{N}$ was detected in our study.

Then the relationships between the genotypes of $\alpha / \beta$ globin mutation and the characteristics of thalassemia mean corpuscular volume (MCV) or mean corpuscular $\mathrm{Hb}(\mathrm{MCH})$ were observed. 407 patients (407/539) with $\alpha$-thalassemia mutation and 867 patients (867/ 1140) with $\beta$-thalassemia mutation had been taken with the hematological analysis. Of the patients with -_SEA / $\alpha \alpha$, the level of MCV and MCH in most cases $(97.4 \%)$ were lower than the normal reference interval 
(MCV $82-100 \mathrm{fL}, \quad M C H \quad 27.0-34.0 \mathrm{pg}$ ), only seven cases had the normal MCV and $\mathrm{MCH}$ value (2.6\%). While among the patients with $-\alpha^{3.7} / \alpha \alpha$, the proportions of the patients with the normal $\mathrm{MCV}$ or $\mathrm{MCH}$ value were 36.3 , $35.2 \%$ respectively, also the similar results were seen in the patients with $-\alpha^{4.2} / \alpha \alpha$ genotype (Table 2 ).

\section{Discussion}

In this study, the thalassemia data were obtained through a large sample of 4889 patients in our hospital from Hubei province, the central region of China. The common thalassemia genotype status in this region was described. The overall frequency of thalassemia mutation carriers was $33.81 \%, 11.0 \%$ of subjects were $\alpha$-thalassemia mutation carriers, $23.3 \%$ of subjects were $\beta$-thalassemia mutation carriers, and $0.51 \%$ of subjects were both $\alpha$ - and $\beta$-thalassemia mutation carriers. The carrier frequency here was higher than that in previous reports in Guangdong (11.33\%) [5] and Guangxi (24.51\%) [12], especially the genotype distribution was different from their reports that the proportion of $\alpha$-thalassemia mutation was near two fold than $\beta$-thalassemia mutation. This discrepancy was probably due to the testing strategy and in the population selected, in our study, the subjects were mainly suspected with thalassemia, most of them with microcytosis, while in some studies, healthy subjects

Table 2 Genotype and hematologic data of thalassemia patients

\begin{tabular}{lllll}
\hline Genotype & MCV < ref & MCV nor & $M C H<$ ref & MCH nor \\
\hline $\begin{array}{l}\text { a-thalassemia } \\
\text {-- SEA /aa }\end{array}$ & 267 & 7 & 267 & 7 \\
$-a^{3.7} /$ aa & 58 & 33 & 59 & 32 \\
$-a^{4.2} / a a$ & 10 & 7 & 10 & 7 \\
Compound heterozygote & 23 & 0 & 23 & 0 \\
homozygote & 1 & 1 & 1 & 1 \\
$\beta$-thalassemia & & & & \\
$\beta I V S-I I-654 / \beta N$ & 383 & 23 & 390 & 16 \\
$\beta C D 41-42 / \beta N$ & 200 & 7 & 201 & 6 \\
$\beta C D 17 / \beta N$ & 123 & 5 & 124 & 4 \\
$\beta C D 27-28 / \beta N$ & 26 & 0 & 26 & 0 \\
$\beta C D 71-72 / \beta N$ & 21 & 1 & 21 & 1 \\
$\beta-28 / \beta N$ & 14 & 3 & 15 & 2 \\
$\beta C D 43 / \beta N$ & 9 & 1 & 10 & 0 \\
$\beta E / \beta N$ & 6 & 2 & 6 & 2 \\
$\beta-29 / \beta N$ & 4 & 2 & 4 & 2 \\
$\beta C D 14-15 / \beta N$ & 3 & 0 & 3 & 0 \\
Compound heterozygote & 15 & 3 & 14 & 4 \\
homozygote & 8 & 2 & 4 & 6 \\
Rare variant & 3 & 2 & 3 & 2 \\
\hline
\end{tabular}

coming for routine healthy examination [6]. Difference in ethnicity may also partially explain the differences. In Guangxi and Hainan, Baise descents or Zhuang people and $\mathrm{Li}$ people were included, in our study, mainly Han people were tested.

$\alpha$-thalassemia is mainly caused by three types of genotypes, including Southeast Asian deletion (-- ${ }^{\text {SEA }}$ deletion), the right deletion $\left(-\alpha^{3.7}\right)$, the left deletion $\left(-\alpha^{4.2}\right)$ in Chinese populations [13]. In the current study, seven $\alpha$-thalassemia genotypes were detected, including _- SEA / $\alpha \alpha,-\alpha^{3.7} / \alpha \alpha,-\alpha^{4.2} / \alpha \alpha,-\alpha^{3.7} /-\alpha^{3.7},-\alpha^{4.2} /-\alpha^{4.2},-\alpha^{3.7} /-$ ${ }_{-}$SEA,$-\alpha^{4.2} /{ }_{-}$SEA . The top genotypes were ${ }_{--}{ }^{S E A} / \alpha \alpha$, $-\alpha^{3.7} / \alpha \alpha$ and $-\alpha^{4.2} / \alpha \alpha$, accounted for $66.05,24.12$ and $3.71 \%$, composing of $93.88 \%$ of all the $\alpha$-thalassemia mutation carriers. The compound heterozygous $-\alpha^{3.7} /-{ }^{3}$ SEA, $-\alpha^{4.2} /-{ }^{2}$ SEA deletions and the homozygous $-\alpha^{3.7} /-\alpha^{3.7}$ and $-\alpha^{4.2} /-\alpha^{4.2}$ deletions accounted for the remaining $6.12 \%$. Consistent with previous studies, -- ${ }^{-}$EA deletion was the main $\alpha$-thalassemia genotype, similar with that in the high incidence provinces such as Guangdong Province [14], Guangxi [15], and the adjacent Hunan Province [16].

$\beta$-thalassemia is mainly caused by point mutations in Chinese populations. The most common mutations include CD41-42, IVS-II-654, CD17, -28 and -29 , accounting for more than $90.0 \%$ of all $\beta$-thalassemia mutations in Chinese population [17]. Twenty-nine $\beta$ globin mutations were detected here. IVS-II-654 and CD41-42 accounted for 47.89 and $24.91 \%$, respectively, followed by CD17, CD27-28 and CD71-72 (13.81, 2.81, and $2.46 \%$, respectively). The distribution of mutation types was significantly different compared with previous reports. For example, CD17 was the most frequent $\beta$ thalassemia mutation with an allele frequency of $40.22 \%$ in this Baise region in Guangxi [6], where CD41-42 was the most common mutation in Guangdong $[18,19]$, and the first two mutations in Hainan Province were CD4142, and IVS-II-654 [7], the top three mutations in Yunnan province were CD26, CD17 and CD41-42 [20]. The above results showed that the distribution of $\beta$ thalassemia mutations had strongly regional and racial specificity, showing different distribution characteristics in different regions and ethnicities.

It has been shown that the characteristic of the thalassemia carriers is microcytosis. The sensitivity of MCV and $\mathrm{MCH}$ for $-\mathrm{SEA}^{\mathrm{SEA}} / \alpha \alpha,-\alpha^{3.7} / \alpha \alpha$, and $-\alpha^{4.2} / \alpha \alpha$ was 97.4 , 63.7, and $58.8 \%$ respectively. Patients with compound heterozygous mutations, the sensitivity of both MCV and $\mathrm{MCH}$ increased to $100 \%$. Compared to the $\alpha$ thalassemia carriers, the overall sensitivity is higher for $\mathrm{MCV}$ and $\mathrm{MCH}$ screening in $\beta$-thalassemia carriers.

Additionally, twenty-five cases with compound $\alpha / \beta$ thalassemia mutations were detected in the current study, $-\alpha^{3.7} / \alpha \alpha$ and $\beta$ IVS-II- $654 / \beta \mathrm{N}$ was the most 
compound $\alpha / \beta$ - thalassemia. Fourteen of them had been with hematological analysis, only eight cases showed mild thalassemia (data not shown). Our results partly support the view that the coinheritance of $\alpha$-thalassemia could ameliorate the severity of $\beta$ thalassemia because it lowers $\alpha$-globin production and reduces the damage to red cells caused by free intracellular $\alpha$-globin [21].

\section{Conclusion}

In conclusion, our data indicated great heterogeneity and extensive spectrum of thalassemias in Hubei province of China.

\section{Abbreviations}

MCV: Mean corpuscular volume; MCH: Mean corpuscular Hb; RDB: PCR-based reverse dot blot

\section{Acknowledgements}

Not applicable.

\section{Authors' contributions}

$J X$ and $Y L$ conceived the experiments and wrote the manuscript. $Y Z$ performed genetic test, NS and XW performed data analyzed and summarized results performed. All authors have read and approved the manuscript.

\section{Funding}

This study was supported by the National Natural Science Foundation of China (No. 81500925). The funding body played no role in the design of the study and collection, analysis, and interpretation of data and in writing the manuscript.

\section{Availability of data and materials}

The datasets generated and/or analysed during the current study are available in the [Pan.baidu.com] repository, [https://pan.baidu.com/s/1 cVou7HaMGEQXcr-_GrfM6g. access code: qpdz].

\section{Ethics approval and consent to participate}

This study was approved guidelines by the Ethics Committee of Tongji Hospital, Tongji Medical College, Huazhong University of Science and Technology. This study was designed as retrospective analysis, only summarized and analysis the whole data, not related to the single patient detailed information. The consent to participate was waived.

\section{Consent for publication}

Not applicable.

\section{Competing interests}

The authors declare that they have no competing interests.

Received: 26 January 2019 Accepted: 15 November 2019

Published online: 06 January 2020

\section{References}

1. Hemminki K, Li X, Forsti A, Sundquist J, Sundquist K. Thalassemia and sickle cell anemia in Swedish immigrants: genetic diseases have become global. SAGE open medicine. 2015;3:2050312115613097.

2. Forget BG. Molecular basis of hereditary persistence of fetal hemoglobin. Ann N Y Acad Sci. 1998;850:38-44.

3. Lai K, Huang G, Su L, He Y. The prevalence of thalassemia in mainland China: evidence from epidemiological surveys. Sci Rep. 2017;7(1):920.

4. He S, Li J, Li DM, Yi S, Lu X, Luo Y, Liang Y, Feng C, Chen B, Zheng C, et al. Molecular characterization of alpha- and beta-thalassemia in the Yulin region of southern China. Gene. 2018;655:61-4.

5. Xu XM, Zhou YQ, Luo GX, Liao C, Zhou M, Chen PY, Lu JP, Jia SQ, Xiao GF, Shen $X$, et al. The prevalence and spectrum of alpha and beta thalassaemia in Guangdong Province: implications for the future health burden and population screening. J Clin Pathol. 2004;57(5):517-22.

6. He S, Qin Q, Yi S, Wei Y, Lin L, Chen S, Deng J, Xu X, Zheng C, Chen B. Prevalence and genetic analysis of alpha- and beta-thalassemia in Baise region, a multi-ethnic region in southern China. Gene. 2017;619:71-5.

7. Yao H, Chen X, Lin L, Wu C, Fu X, Wang H, Yao Z, Chen W, Huang L, Tang R, et al. The spectrum of alpha- and beta-thalassemia mutations of the Li people in Hainan Province of China. Blood Cells Mol Dis. 2014;53(1-2):16-20.

8. Weatherall DJ, Clegg JB. Inherited haemoglobin disorders: an increasing global health problem. Bull World Health Organ. 2001;79(8):704-12.

9. Cai WQ, Hu XJ, Xiong Q, Zhou B. Prevalence and genotype analysis of newborn alpha-thalassemia in Wuhan area of China. Zhongguo shi yan xue ye xue za zhi. 2018;26(1):219-22.

10. Xiong Q, Hu XJ, Dai X, Zhou B, Cai WQ. Prevalence and genetic analysis of beta-thalassemia in neonates in Wuhan area of China. Zhongguo shi yan xue ye xue za zhi. 2019;27(1):170-4.

11. Xu C, Liao B, Qi Y, Huangfu Z, Chen J, Chen Y. Analysis of gene mutation types of alpha- and beta-thalassemia in Fuzhou, Fujian Province in China. Hemoglobin. 2018;42(3):143-7.

12. Xiong F, Sun M, Zhang X, Cai R, Zhou Y, Lou J, Zeng L, Sun Q, Xiao Q, Shang $X$, et al. Molecular epidemiological survey of haemoglobinopathies in the Guangxi Zhuang autonomous region of southern China. Clin Genet. 2010;78(2):139-48.

13. Chong SS, Boehm CD, Higgs DR, Cutting GR. Single-tube multiplex-PCR screen for common deletional determinants of alpha-thalassemia. Blood. 2000;95(1):360-2.

14. Zhao P, Weng R, Wu H. Molecular Spectrum of alpha- and beta-thalassemia mutations in a large ethnic Hakka population in southern China. Hemoglobin. 2018;42(2):117-21.

15. Tang W, Zhang C, Lu F, Tang J, Lu Y, Cui X, Qin X, Li S. Spectrum of alphathalassemia and beta-thalassemia mutations in the Guilin region of southern China. Clin Biochem. 2015;48(16-17):1068-72.

16. He J, Zeng H, Zhu L, Li H, Shi L, Hu L. Prevalence and spectrum of thalassaemia in Changsha, Hunan province, China: discussion of an innovative screening strategy. J Genet. 2017;96(2):327-32.

17. Chen PQ, Liang QN, Huang TS, Liu TC, Li M. A simple, rapid, and highly sensitive electrochemical DNA sensor for the detection of alpha- and betathalassemia in China. J Clin Lab Anal. 2016;30(5):719-26.

18. Zhang CM, Wang Y, Gao LS, Gao JH, He XL, Feng HJ, Liao JL. Molecular epidemiology investigation of beta-thalassemia in Zhongshan City, Guangdong Province People's Republic of China. Hemoglobin. 2010;34(1):55-60.

19. Yin A, Li B, Luo M, Xu L, Wu L, Zhang L, Ma Y, Chen T, Gao S, Liang J, et al. The prevalence and molecular spectrum of alpha- and beta-globin gene mutations in 14,332 families of Guangdong Province China. PloS one. 2014; 9(2):e89855.

20. Zhang J, Zhu BS, He J, Zeng XH, Su J, Xu XH, Li SY, Chen H, Zhang YH. The spectrum of alpha- and beta-thalassemia mutations in Yunnan Province of southwestern China. Hemoglobin. 2012;36(5):464-73.

21. Thein SL. Genetic association studies in beta-hemoglobinopathies. Hematology American Society of Hematology Education Program. 2013; 2013:354-61.

\section{Publisher's Note}

Springer Nature remains neutral with regard to jurisdictional claims in published maps and institutional affiliations.

\section{Ready to submit your research? Choose BMC and benefit from}

- fast, convenient online submission

- thorough peer review by experienced researchers in your field

- rapid publication on acceptance

- support for research data, including large and complex data types

- gold Open Access which fosters wider collaboration and increased citations

- maximum visibility for your research: over $100 \mathrm{M}$ website views per year

At BMC, research is always in progress.

Learn more biomedcentral.com/submission 